\title{
"Reconnecting cities to the biosphere: Stewardship of green infrastructure and urban ecosystem services" - where did it come from and what happened next?
}

\author{
This article belongs to Ambio's 50th Anniversary Collection. Theme: Urbanization
}

\author{
Erik Andersson
}

Cities understood as social-ecological systems have a long history within different disciplines, represented for example by ecology in and of cities, landscape urbanism and the political ecology of urban metabolism. However, in my field-natural resources management grounded in resilience theory, systems ecology and studies of institutional frameworks - urban studies started to gain interest in the late 1990s and early 2000s. For us, the group I was working in at Stockholm University, urban social-ecological studies started in earnest with the work on and for the Millennium Ecosystem Assessment. I only joined at the end, but what we felt at the time was that while systematic and systemic in its scope, the Millennium Ecosystem Assessment was also broad and vague: it allowed you to put a number of concepts, ideas and perspectives under the same umbrella-what it did not was to solidly connect them, or capture their details. After the work with Millennium Ecosystem Assessment, we went deep-and at least when starting out-narrow. During 2003-2012 we investigated, often in parallel, a number of the components of identified as important in the assessment. These included different types of ecosystem services, the role of knowledge and different stewardship arrangements and the consequences of different urbanisation strategies among other things, and these studies added more nuance to the multiple connections between people and the partly green urban landscapes they live in. These investigations led in turn to new questions and new projects. What all the studies shared was a rough systems framework grounded in the work by Holling (1973), Holling and Meffe (1996), Berkes and Folke (1998), Ostrom (1999, 2009) and Berkes et al. (2003). The systems approach meant the individual studies over time expanded and slowly began to merge as we identified more solid connections between topics and different lines of investigation. With time, we developed a good understanding of what the many-often wicked-challenges inherent in creating liveable and sustainable cities are, an understanding that we used to increasingly engage in transdisciplinary endeavours to find solutions.

Through our work, led by a wish to be relevant also to practitioners and non-researchers with an interest in cities and ways forward for making them more sustainable, we built and expanded a transdisciplinary foundation for collaborating with other actors in the Stockholm region. The different collaborations of course helped deepen and develop our research, and it also opened up a new, parallel line of investigation-how to effectively co-produce actionable knowledge(s) through different fora and with diverse and often changing partners. This led to increased uptake of our ideas in practice, which in turn led to new opportunities to revise and further develop our theories and ideas. As the 'system' started to come together, and with a better understanding of different 'problem contexts', we could also start to not only proposing solutions to individual problems but also more systemic principles fitting solutions together.

Why then the paper? If there need to be a reason beyond sharing knowledge and further the overall understanding of a complex issue... The early 2010s was a time when Stockholm Resilience Centre (Stockholm University) and the Beijer Institute of Ecological Economics (the Royal Swedish academy of Sciences), where I (and most of my co-authors) was working at the time, went through a period of taking stock and synthesising insights from different case study areas and lines of research. The 2014 paper (Andersson et al. 2014) was an output from this process and, importantly, another opportunity to present more of a consolidated idea of what our approach was. We positioned ecosystem service generation in urban landscapes as framed and enabled by ecological character as well as 
stewardship and institutions (e.g., property rights), social networks and involvement of local user groups and civil society in green area management and governance) and thus where it might fit in with other ongoing, international work. While the basis for the studies and analyses behind Andersson et al. (2014) has always been the larger system-the structural backbone and the dynamic properties of a complex social-ecological system-the 2014 paper had a clear actor focus. Not least in that the paper foregrounded stewardship as an important activity as well as worldview. What the study did not do, was to engage with the arguably implicit normativity of stewardship, nor with the many additional aspects that an actor-advocacy perspective arguably need to acknowledge. Since the article was published, justice and power issues as well as the art of participatory research and knowledge creation and sharing have moved much forward and had it been written today, this is one of the things we would have expanded on. Nevertheless, the article helped me position my interests and myself. Over the last 6 years since the paper appeared in Ambio, I have worked extensively in different collaborations to further expand the ideas presented in the paperand to be involved in multiple discussions about future urbanisation, within academia and outside. In short, the paper was a good early mid-career investment.

Many of the threads and insights from the paper have continued to develop since 2014. There are three that I am particularly happy with: Firs, the progress made on developing stewardship as a concept and analytical lens (e.g. Buijs et al. 2016; Andersson et al. 2017; Peçanha Enqvist et al. 2018). Second, the development of a spatially explicit approach to SES (or SETS, social-ecologicaltechnological systems, in recognition of technology as both a critical factor and a bridge to other disciplines) embedding urban nature in the built up parts of the city, the institutional context and in the minds of its inhabitants (e.g. Andersson et al. 2019). Finally, related to the first two, the understanding of the diversity of ways the urban system generate ecosystem service benefits. Stewardship and collaborative management, especially set in a complex urban environment, were at the core of the studies leading up to the 2014 paper. They point to the role of nature in cities for people and vice versa, what activities and benefits it affords and how these connect to people's values and behaviour at scales beyond their more immediate surroundings. Stewardship as a self-reinforcing combination of care, knowledge, motivation, agency and action that can nurture and be nurtured by ecologically rich urban green and blue infrastructure I feel is still one of the strongest arguments for green cities. Although evidence still is inconclusive and somewhat ambiguous, there is growing support for the role of a close relation to nature and our overall exposure to and experience of urban ecosystems for how we think about and act towards nature in general, also in abstract distant places (e.g. Miller 2005; Ives and Kendal 2014). To paraphrase what we wrote in 2014 , and which remains true: "Cities arguably need to reduce their ecological footprint, but perhaps more importantly the character of the footprint needs to change. A crucial step is to provide within-city opportunities for responsible stewardship to help reconnect citizens to the biosphere. In general, the promotion of " cognitive resilience building', for ecosystem stewardship in urban areas is central [...]. It implies the perceptions, memory, and reasoning that people acquire from frequent interactions with local ecosystems, shaping peoples' experiences, world views, and values toward local ecosystems and ultimately toward the biosphere." (p. 451)

The 2014 paper recognised the inherent differences across ecosystem services and in how we draw benefit from them, and argued for more attention to this diversity. Already the year before, my colleague Henrik Ernstson (2013) had described how ecosystem services are not benefits of nature (only) but very much co-produced by people and society. Later work has described the different ways people and nature-and especially in the city our built up infrastructure-together create and constrain opportunities to benefit from urban ecosystems. This deeper understanding is opening up the field for a more sophisticated discussion about environmental and social justice (e.g. Langemeyer and Connolly 2020) and what it will take to make our cities both resilient to future changes and fairer in how quality of life is distributed within and across them. Ecosystem services are increasingly 'mainstreamed' into policy, often superficially, and this work on the diverse preconditions and processes needed is a much needed entry point for fully integrating urban ecosystems into (sustainable) urban development planning and practice.

In addition to contributing to the development of our understanding of the complex phenomenon of urbanisation, the work with the 2014 paper was important for me personally in terms of how I now do research. Although it may not be evident from reading the paper (which has a rather traditional synthesis organisation), the 2014 paper was an early step towards internal reflexion and critical evaluation-repositioning and re-evaluation of earlier findings that I quite appreciated and have since developed and turned into a more structured, ever on-going analytical side of my work.

And finally, the 2014 article, as well as all the work it builds on, was very much an outcome of a long term collaboration among the authors and beyond. Agreeing and disagreeing with you have been - and continues to be-a pleasure. 


\section{REFERENCES}

Andersson, E., S. Barthel, S. Borgström, J. Colding, T. Elmqvist, C. Folke, A. Gren, and A. Gren. 2014. Reconnecting cities to the biosphere: Stewardship of green infrastructure and urban ecosystem services. Ambio 43: 445-453. https://doi.org/10. 1007/s13280-014-0506-y.

Andersson, E., J. Enqvist, and M. Tengö. 2017. Stewardship in urban landscapes. In The science and practice of landscape stewardship, ed. C. Bieling and T. Plieninger, 222-238. Cambridge: Cambridge University Press. https://doi.org/10.1017/ 9781316499016.023.

Andersson, E., J. Langemeyer, S. Borgström, T. McPhearson, D. Haase, J. Kronenberg, D.N. Barton, M. Davis, et al. 2019. Enabling green and blue infrastructure to improve contributions to human well-being and equity in urban systems. BioScience 69: 566-574. https://doi.org/10.1093/biosci/biz058.

Berkes, F., and C. Folke. 1998. Linking social and ecological systems: Management practices and social mechanisms for building resilience. Cambridge: Cambridge University Press.

Berkes, F., J. Colding, and C. Folke (eds.). 2003. Navigating socialecological systems: Building resilience for complexity and change. Cambridge: Cambridge University Press.

Buijs, A., T.J. Mattijssen, A.P. Van der Jagt, B. Ambrose-Oji, E. Andersson, B.H.M. Elands, and M. Steen Møller. 2016. Active citizenship for urban green infrastructure: Fostering the diversity and dynamics of citizen contributions through mosaic governance. Current Opinion in Environmental Sustainability 22: 1-6. https://doi.org/10.1016/j.cosust.2017.01.002.

Ernstson, H. 2013. The social production of ecosystem services: A framework for studying environmental justice and ecological complexity in urban landscapes. Landscape and Urban Planning 109: 7-13.

Holling, C.S. 1973. Resilience and stability of ecological systems. Annual Review of Ecology and Systematics 4: 1-23.
Holling, C.S., and G.K. Meffe. 1996. Command and control and the pathology of natural resource management. Conservation Biology 10: $328-337$.

Ives, C.D., and D. Kendal. 2014. The role of social values in the management of ecological systems. Journal of Environmental Management 144: 67-72.

Langemeyer, J., and J.J.T. Connolly. 2020. Weaving notions of justice into urban ecosystem services research and practice. Environmental Science and Policy. https://doi.org/10.1016/j.envsci. 2020.03.021.

Miller, J.R. 2005. Biodiversity conservation and the extinction of experience. Trends in Ecology \& Evolution 20: 430-434.

Ostrom, E. 1999. Linking social and ecological systems: Management practices and social mechanisms for building resilience. Ecological Economics 28: 151-153.

Ostrom, E. 2009. A general framework for analyzing sustainability of social-ecological systems. Science 325: 419-422.

Peçanha Enqvist, J., S. West, V.A. Masterson, L.J. Haider, U. Svedin, and M. Tengö. 2018. Stewardship as a boundary object for sustainability research: Linking care, knowledge and agency. Landscape and Urban Planning 179: 17-37. https://doi.org/10. 1016/j.landurbplan.2018.07.005.

Publisher's Note Springer Nature remains neutral with regard to jurisdictional claims in published maps and institutional affiliations.

\section{Erik Andersson ( $\square)$}

Address: Stockholm Resilience Centre, Stockholm University, Stockholm, Sweden.

Address: Unit for Environmental Sciences, North-West University, Potchefstroom, South Africa.

e-mail: erik.andersson@su.se 